\title{
A Note on the Stability Properties of Goodwin's Predator-Prey Model ${ }^{*}$
}

\author{
Luís Aguiar-Conraria \\ E-mail:1faguiar@eeg.uminho.pt \\ NIPE, Economics Department, Universidade do Minho
}

\author{
Address \\ Departamento de Economia \\ Universidade do Minho \\ Escola de Economia e Gestão \\ Campus de Gualtar \\ 4710-057 Braga
}

\footnotetext{
* I am indebted to Francisco Louçã, the editorial coordinator Christophre Georges and three referees for helpful comments. I thank Ana Isabel Dias - Scientific Editing Programme of Universidade do Minho - for revising the text. The usual disclaimer applies.
} 


\title{
A Note on the Stability Properties of Goodwin's Predator- Prey Model
}

\author{
Abstract \\ Goodwin's Predator-Prey model is structurally unstable. In its pure form, the model has an \\ equilibrium that is neither stable nor unstable. Ploeg showed that relaxing the hypothesis of \\ fixed proportion technology would stabilize the equilibrium. On the other hand, Goodwin \\ showed that the equilibrium becomes unstable when endogenous productivity growth is \\ considered. This paper studies the consequences of considering both effects, and concludes \\ that the stabilizing effect of a flexible technology is much stronger than the destabilizing \\ effect of endogenizing labor productivity.
}

Keywords: Business cycles, nonlinear dynamics, distributive conflict, Goodwin, Marxian Economics

JEL classification: B51, C62, E11, E32

\section{Introduction}

Since the works of Slutsky and Frisch, most mainstream macroeconomists understand the business cycle as comprising two distinct features: the impulse (a stream of exogenous shocks) and the propagation mechanism (an oscillating stable system).

There is an alternative approach, popularized by Kalecki, Kaldor, Goodwin and many others. These authors use nonlinear systems to generate self-fulfilling business cycles. Instability and fluctuations are endogenous to the economic system. These authors do not exclude the existence of exogenous shocks, but argue that fluctuations occur even in the 
absence of those shocks. Entrenched in this tradition, Goodwin would present in 1967 what became his most celebrated model. Goodwin's predator-prey growth cycle model. ${ }^{1}$

Goodwin (1967)'s model describes an antagonistic relationship between workers and capital owners. Goodwin imported a predator-prey model from biology to give form to this class struggle. The Marxian inspiration is clear: in a situation of rising profitability, investment will be raised, creating more jobs and destroying the reserve army of labor. This will give more bargaining power to labor, which can demand higher wages. The increasing wages will imply decreasing profits and thus accumulation slackens, leading to an increase in unemployment, reducing wages and raising profitability: a new cycle begins.

Goodwin's model is structurally unstable. ${ }^{2}$ In fact, slight modifications lead to significant changes in the properties of the model. In this study, Goodwin's model is approached as a special case of a more general framework, permitting the evaluation of the effects of relaxing some assumptions. This paper concludes that Goodwin's model is only one step away from the Slutsky-Frisch paradigm.

\section{The Model}

Goodwin made five assumptions for convenience (in his words) and two assumptions of a disputable sort. The first five: (i) productivity of labor growing exogenously at rate $\beta$, (ii) steady growth of labor force, (iii) two factors of production, both homogenous, (iv) all quantities real and net, and (v) all wages consumed and all profits invested.

\footnotetext{
${ }^{1}$ Although this model became a classic, with the notable exception of Desai (1984), Solow (1990) was the first to empirically test Goodwin's model. The displacements were so large that Solow could not accept it. Harvie (2000) tested the model with ten OECD countries (Australia, Canada, Finland, France, Germany, Greece, Italy, Norway, the United Kingdom and the United States). The model performed quite well for all countries except for the United States and United Kingdom.

2 See Veneziani (2001) for a detailed survey on the structural instability of Goodwin's model.
} 
Considering the exogenous steady growth of the labor force to be zero does not change the final results, therefore that simplification is made. Considering the total standardized workforce to be 1 , the total employment and the employment rate are the same $(=L)$. A Kaldorian technical progress function is considered here since it allows the efficiency of labor to be influenced by the size of the capital stock $(=\mathrm{K})$. The effective labor force is:

$$
L_{e f}=L e^{\beta t} K^{\gamma}
$$

Goodwin (1991) used a similar extension to the original 1967 model. To be more precise, Goodwin assumed that labor productivity would grow according to $\frac{\dot{a}}{a}=\beta+\gamma \frac{\dot{K}}{K}$. This extension makes the model unstable (generating explosive oscillations). To restrict the system to a compact set, Goodwin (1991) introduced a differential equation with a control variable. Goodwin's system of three nonlinear differential equations was able to generate chaotic motions. ${ }^{3}$ To impose growth, Goodwin added a logistic equation for investment, representing a Schumpeterian swarm of innovations, which induced a Kondratiev wave.

The two assumptions of disputable sort were: (i) constant capital-output ratio, and (ii) real wage rises in the neighborhood of full employment (a real wage Phillips curve).

The latter assumption implies:

$$
\frac{\dot{w}}{w}=f(L)
$$

I allow, like Goodwin and Desai et al (2006), that the function becomes indefinitely large as $L$ approaches 1 . The function has a negative lower bound for low values of $L$. In the

\footnotetext{
${ }^{3}$ Sordi (1999) shows that if a discrete time version of the model is considered, chaotic dynamics are possible even in a two dimensional system.
} 
economic literature it is usual to consider two types of models to explain the existence of this type of wage curve: bargaining and efficiency wage models. In a bargaining model, a low employment rate frightens workers, reducing their ability to claim for a large share of the surplus to be divided. If we rely on the efficiency wage theory, see Shapiro and Stiglitz (1984), we accept that wages have a positive influence on productivity. In equilibrium, firms maximize profits, and workers choose their effort. The unemployment rate plays a crucial role: it affects the probability a sacked worker has of getting another job.

The constant capital-output ratio assumption is replaced by a general CES production function:

$Y=\left[\alpha K^{-\delta}+(1-\alpha) L_{e f}^{-\delta}\right]^{-\frac{1}{\delta}}$

As $\delta$ approaches zero, the function becomes a Cobb-Douglas production function, and as $\delta$ approaches infinity, it becomes a Leontief production function (Goodwin's assumption).

Like Ploeg (1985), I assume profit maximization; therefore firms hire workers until their marginal productivity equals the wage:

$$
\begin{aligned}
& \frac{\partial Y}{\partial L}=w \\
& \frac{\partial Y}{\partial L_{e f}}=w e^{-\beta t} K^{-\gamma}
\end{aligned}
$$

From equation (4), I am able to determine the optimal factor demand ratio (in effective terms), the optimal capital-output ratio $(\sigma)$, and labor productivity $(a)$ : 


$$
\left\{\begin{array}{c}
\left(\frac{K}{L_{e f}}\right)(u)=\left(\frac{(1-\alpha)(1-u)}{\alpha u}\right)^{-\frac{1}{\delta}} \\
\frac{K}{Y}=\sigma(u)=\left(\frac{a}{(1-u)}\right)^{\frac{1}{\delta}} \\
\frac{Y}{L}=a(u)=\left(\frac{u}{1-\alpha}\right)^{\frac{1}{\delta}} e^{\beta t} K^{\gamma}
\end{array}\right.
$$

where $u=(w / a)$ represents worker's proportion of national income. It is possible to describe the model with two differential equations representing the evolution of labor's share of national income and of the employment rate:

$$
\left\{\begin{array}{l}
\frac{\dot{u}}{u}=\frac{\dot{W}}{W}-\frac{\dot{a}}{a} \\
\frac{\dot{L}}{L}=\frac{\dot{K}}{K}-\frac{\dot{k}}{k}
\end{array}\right.
$$

where $k=\frac{K}{L}$. Using the above-derived equations, and noting that all profits are invested, $\dot{K}=(1-u) Y$, we get:

$$
\left\{\begin{array}{l}
\frac{\dot{u}}{u}=\left(f(L)-\beta-\gamma \alpha^{-\frac{1}{\delta}}(1-u)^{\frac{1+\delta}{\delta}}\right) \frac{\delta}{1+\delta} \\
\frac{\dot{L}}{L}=(1-\gamma) \alpha^{-\frac{1}{\delta}}(1-u)^{\frac{1+\delta}{\delta}}-\frac{1}{\delta(1-u)} \frac{\dot{u}}{u}-\beta
\end{array}\right.
$$

\section{The Properties}

The original predator-prey model is just a special case of the system of equations (7). Letting $\gamma=0$, taking limits as $\delta \rightarrow+\infty$, and taking a linear approximation of the wage curve $(f(L) \approx-\phi+\rho L)$, the resulting model is formally equivalent to the Lotka-Volterra 
predator-prey model: $\left\{\begin{array}{c}\dot{u}=(-\beta-\phi+\rho L) u \\ \dot{L}=((1-u)-\beta) L\end{array}\right.$. The properties of this special case are perfectly known. It has an equilibrium point that is neither stable nor unstable: if the system is close to the equilibrium point, there will be no force pushing it off course, so it is not an unstable equilibrium; on the other hand, if the system is in disequilibrium, there will be no force pulling it to the equilibrium state, so it is not a stable equilibrium. It is clear that the crucial assumption of this model is the real-wage Phillips curve: it is the evolution of real wages that determines the evolution of labor's share of national income, and it is the evolution of labor's share that determines the level of investment. Note that if the exogenous rate of technical progress, $\beta$, is zero, the dynamic properties of the system do not change. Thus, Aghion's and Howitt's belief (Aghion and Howitt, 1998) that this was the first model in which cycles are a deterministic consequence of the growth process seems incorrect.

If we consider a CES production function $(\delta<+\infty)$, and keep $\gamma=0$, we are allowing some substitutability between labor and capital. The economic system becomes more flexible. Ploeg (1985) showed that the rest point of the system becomes stable. A re-edition of the debate between Solow and Harrod-Domar: when it is considered a production function with zero elasticity of substitution, the system does not approach the equilibrium point, just as in the Harrod-Domar growth model. With some substitutability, the equilibrium is no longer unstable and the system approaches a steady state, as in the Solow growth model.

On the other hand, if we keep $\delta \rightarrow+\infty$, but allow $\gamma>0$ we observe the opposite effect. As in the original model, in a situation of increasing profitability, investment is raised and more workers are hired. But this increase in investment also has a positive effect on labor productivity, which increases profits even further, and hence investment will be higher than 
otherwise. On the other hand, when accumulation slackens, labor productivity is negatively affected, and profits will be even lower. Mathematically, the rest point becomes locally unstable, and the system generates (locally) explosive cycles. ${ }^{4}$

Considering the general case, a CES production function and the efficiency of labor being (positively) influenced by the stock of capital, the economic system is described by the system of equations (7). The rest point is given by $u^{*}=1-(\beta /(1-\gamma))^{\delta /(1+\delta)} \alpha^{1 /(1+\delta)}$ and $L^{*}=f^{-1}(\beta / 1-\gamma)$. Linearizing the system around the steady state, system (7) becomes:

$$
\left\{\begin{array}{l}
\dot{u}=\gamma\left(\frac{1-u^{*}}{\alpha}\right)^{\frac{1}{\delta}} u *\left(u-u^{*}\right)+\frac{f^{\prime}(L) u^{*} \delta}{1+\delta}\left(L-L^{*}\right) \\
\dot{L}=\left((1+\delta)(\gamma-1)-\frac{\gamma}{\left(1-u^{*}\right)}\right)\left(\frac{1-u^{*}}{\alpha}\right)^{\frac{1}{\delta}} \frac{L^{*}}{\delta}\left(u-u^{*}\right)-\frac{f^{\prime}\left(L^{*}\right) L^{*}}{(1+\delta)\left(1-u^{*}\right)}\left(L-L^{*}\right)
\end{array}\right.
$$

The characteristic equation of the above linear system of differential equations is

$$
\lambda^{2}+\left[\frac{f^{\prime}\left(L^{*}\right) L^{*}}{(1+\delta)\left(1-u^{*}\right)}-\gamma\left(\frac{1-u^{*}}{\alpha}\right)^{\frac{1}{\delta}} u^{*}\right] \lambda+(1-\gamma)\left(\frac{1-u^{*}}{\alpha}\right)^{\frac{1}{\delta}} u^{*} L^{*} f^{\prime}\left(L^{*}\right)=0
$$

The constant is positive, so it is the sign of the term in square brackets that will determine the stability of the system. The consideration of a pro-cyclical productivity growth $(0<\gamma<1)$ has a destabilizing effect while the consideration of a non-null substitutability between factors has a stabilizing effect. Which one prevails will depend on their magnitudes.

\footnotetext{
${ }^{4}$ The model is also globally unstable. To stabilize the system, one could impose a ceiling, or a floor, to one of the variables, avoiding the explosion in the evolution of the system.
} 
If $\gamma>\frac{f^{\prime}\left(L^{*}\right) L^{*}}{u^{*}(1+\delta)\left(1-u^{*}\right)}\left(\frac{\alpha}{1-u^{*}}\right)^{\frac{1}{\delta}}$ then the system is (locally) unstable. Otherwise the model will show damped oscillations approaching the steady state. In case of equality, the system would have closed orbits, like in Goodwin's original model.

The main conclusion can be illustrated with a simple example. Consider: $\beta=0.02$, $\gamma=0.3, \alpha=0.5$, and $f(L)=-0.040064+\frac{0.000064}{(1-L)^{2}} .5$ With these values the system will be stable for $\delta<522$, implying an elasticity of substitution between factors of $\frac{1}{1+\delta}>0.0019$. Even with $\gamma=0.95$, the system is stable if the elasticity of substitution is higher than 0.0032 . These values are several orders of magnitude below an admissible empirical range ${ }^{6}$. Therefore, even for an extremely low substitutability between factors, the system tends to be stable. Changing $\alpha$ between 0.1 and 0.75 , or $\beta$ between 0.01 and 0.075, has nearly no impact.

\section{Conclusion}

Goodwin's Predator-Prey model is structurally unstable. In its pure form, the model represents an economy moving in closed orbits. Ploeg (1985) showed that relaxing the hypothesis of fixed proportion technology would stabilize the equilibrium; Goodwin (1991) showed that endogenizing productivity growth has the opposite effect.

\footnotetext{
${ }^{5}$ Assuming this formulation to the Phillips curve guarantees a lower bound for wages growth (-4\%). For $L=$ 0.96 wages growth rate become zero. This curve becomes indefinitely large as the employment rate approaches 1. Locally, the specific form of $f($.$) is irrelevant. Globally, Desai et al (2006) showed that this$ functional form of the Phillips curve avoids an inconsistency in the original Goodwin model, in which both the labour share and the proportion employed could exceed unity.

${ }^{6}$ Berndt (1976) estimated a unit value for the elasticity of substitution of an aggregate production function for the United States. Kalt (1978) estimated a lower value, 0.76. In a more recent study, Antràs (2004) reexamined Berndt and Kalt estimations, and concluded that the elasticity of substitution ranges from 0.5 and 0.95 .
} 
I have analyzed both effects in a more general framework. The stabilizing effect of introducing some flexibility in the production function is much stronger than the destabilizing effect of endogenous productivity growth. Only when the production function is extremely close to a Leontief technology does the system generate perpetual (and explosive) oscillations. 


\section{References}

[1] Aghion, P. and Howitt, P. (1998), Endogenous Growth Theory, Cambridge, Massachusetts: MIT Press.

[2] Antràs, P. (2004), "Is the U.S. Aggregate Production Function Cobb-Douglas? New Estimates of the Elasticity of Substitution", Contributions to Macroeconomics, vol.4, n. 3 , article 4 .

[3] Berndt, E. (1976), "Reconciling Alternative Estimates of the Elasticity of Substitution", Review of Economics and Statistics, vol. 58, n. 1, pp. 59-68.

[4] Desai, M. (1984). "An econometric model of the share of wages in national income: UK 1855-1965", in Nonlinear Models of Fluctuating Growth, Goodwin, R. M., Vercelli, A., and Kruger, M. (Editors), Berlin: Springer.

[5] Desai, M., Henry, B., Mosley, A. and Pemberton. M. (2006), "A clarification of the Goodwin model of the growth cycle", Journal of Economic Dynamics and Control, vol.30, n. 12, pp 2661-2670.

[6] Goodwin. R. (1967), "A Growth Cycle", in Socialism, Capitalism and Economic Growth, C. H. Feinstein (editor), pp. 54-58, Cambridge University Press.

[7] Goodwin, R. (1991), "Economic Evolution, Chaotic Dynamics and the Marx-KeynesSchumpeter System", in Rethinking Economics: Markets, Technology and Economic Evolution, chapter 9, Edward Elgar, pp. 138-152.

[8] Harvie, D. (2000), "Testing Goodwin: Growth Cycles in Ten OECD Countries", Cambridge Journal of Economics, vol.24, n. 3, pp. 349-376.

[9] Kalt, J. (1978), "Technological Change and Factor Substitution in the United States: 1929-1967”, International Economic Review, vol. 19, n.3, pp. 761-775.

[10] Ploeg, F. Van der (1985), "Classical Growth Cycles", Metroeconomica, vol. 37, n. 2, pp. 221-230.

[11] Shapiro, C. and Stiglitz, J. (1984), "Equilibrium Unemployment as a Worker Discipline Device”, American Economic Review, vol. 74, n. 3, pp. 433-444.

[12] Solow, R. (1990), "Goodwin's Growth Cycle: Reminiscence and Rumination", in Nonlinear and Multisectoral Macrodynamics: Essays in Honour of Richard Goodwin, Velupillai, K. (editor), Chapter 4, pp. 31-41, Macmillan. 
[13] Sordi, S. (1999), "Economic models and the relevance of "chaotic regions": An application to Goodwin's growth cycle model", Annals of Operations Research, vol. 89, pp. 3-19.

[14] Veneziani, R. (2001), "Structural Stability and Goodwin's A Growth Cycle. A Survey", Ente per gli studi monetari, bancari e finanziari "Luigi Einaudi". Temi di ricerca, n. 24. 